\title{
ON THE USE OF PARASITES IN THE CONTROL OF FOREST INSECTS
}

\author{
J. J. DEGRYSE, \\ Acting Chief, Division of Forest Insects
}

$\prod$

HE more thoroughly we understand the transcendental economy arising out of the relations of the proverbial dog to its flea, and the flea to its own flea, the better shall we be prepared to deal with dogs and fleas and all other such interdependents, as trees and insects, hosts and parasites, parasites and hyperparasites. The study of food cycles is not a recent innovation in biology, perhaps it owes much of its present vogue to Darwin whose classical example connecting the abundance of clover with that of cats is not only often quoted but has been extended by some to include the ever popular old maid. Be this as it may, the scientific approach to problems in applied biology to-day is very largely through the study of ecological relationships and in the majority of cases their solution is found therein. The underlying natural philosophy and the methods of procedure are primarily the concern of the scientist. His sponsors, the business man among others, are mainly interested in achievements and practical results. It is the object of this paper to show as briefly as possible not only what has been done but also what must be done along these lines in that branch of biology known as Forest Entomology. It will be readily understood that whilst reference is made here to biological control, more specifically, to control by parasites, there is no intention of belitting the importance of other types of practical control work. Moreover, we shall deal only with some of the more striking examples of work done in Canada. To date, parasites have mostly been used as control agents against pests introduced from other countries. The first problem dealt with in this country, was that of the European larch sawfly, Lygoenematus erichsonii $\mathrm{Hg}$. Between the years 1880 and 1890 this insect destroyed nearly all the larch stands of merchantable size east of the Great Lakes. Later it was found spreading westward through the Paririe provinces into the Yukon. Still more recently it has been reported in outbreak form in stands of western larch in southern British Columbia. Between 1909 and 1913, the parasite Mesoleius tenthredinis $\mathrm{Htg}$. was imported from England by Dr. C. G. Hewitt, then Dominion Entomologist, in the hope of stemming the tide of the advancing infestation. Liberations were made in several localities in New Brunswick, Quebec, Ontario and Manitoba. For a long time nothing noteworthy seemed to have happened and this first attempt at control by the introduction of parasites was almost forgotten. It was not until several years afterward, in the late twenties, that the larch sawflies 
began again to appear in greater numbers than usual in Manitoba. This time, however, before any serious damage was caused the sawfly population became rapidly reduced and at the same time, the parasite, Mesoleius, was found present in large numbers as far as 200 miles from the original point of liberation. In 1932, Dr. J. M. Swaine, referring to this incident in his excellent paper on "The Relation of Insect Activities to Forest Development," states as follows: "How much the imported parasites have had to do with reducing the numbers of the sawfly cannot yet be determined. It is possible that native parasites may have recently become more effective. The cautious attitude adopted by Dr. Swaine was fully justified. Circumstantial evidence pointed strongly to the parasites as the cause of the disappearance of the sawfly in Manitoba, yet, the details in the case had not been followed with sufficient accuracy to warrant a positive statement to that effect. Since then, however, new evidence has been brought to light. The sequence of events witnessed in Manitoba is at present being duplicated in certain areas of the province of Quebec, notably in the Parke Reserve district. Systematic collections of sawfly cocoons in the Quebec larch stands furnish ample justification for attributing the control of the sawfly principally, if not exclusively, to the action of Mesoleius.

In 1910, an infestation of the notorious European browntail moth was reported from New Brunswick. In subsequent years this insect spread to many parts of that province and into Nova Scotia. Between 1912 and 1916 parasites were imported from Europe to combat the pest. Thanks to an active eradication campaign instituted at the same time, the browntail moth soon ceased to be a menace. Meanwhile, however, one of the introduced parasites, Compsilura concinnata, $\mathrm{Mg}$. became established on a number of native species and remained active long after the disappearance of the browntail. The interesting feature in the chain of events became evident only several years later, when another European insect, the Satin moth was discovered in Canada. This latter pest now occurs on poplar and willow in British Columbia and in the Maritime provinces and has multiplied to an alarming extent in several localities. In the east, however, its progress has been quite effectively retarded in all places where the parasite Compsilura concinnata became established as a result of introductions originally made for the control of the browntail, whilst in British Columbia, the very latest reports indicate that, in the region about Seton Lake and in the lower Fraser Valley another imported parasite, Apanteles solitarius Ratz. has multiplied to such an extent that the Satin Moth appears to be definitely under control.

A third and most striking instance of control by parasites is that of the European scale, Lecanium coryli L. Some years ago this insect became very destructive on shade trees in the city of Vancouver and the adjacent 
district. In 1928 and 1929, the parasite Blastothrix sericea Mayr., was received from the Farnham House laboratory in England and was liberated in the infested district. After four years, the parasite had become so thoroughly established that the scale was pracically exterminated.

The above three cases are clear-cut examples of what has been and can be accomplished by the use of insect parasites in controlling outbreaks of forest insects. Other attempts and experiments have been made, but a final statement concerning results would, as yet, be premature. The success or failure of parasite introductions depends on a large number of factors some of which are only imperfectly known at the present time. Nevertheless, in the face of past accomplishments, the intrinsic value of such introductions cannot be reasonably called into doubt any ionger. Among the problems calling for immediate action in Canada, that of the recently discovered European larch sawfly in southern British Columbia and the tremendous outbreak of the spruce sawfly, Diprion polytomum, in the Gaspe are outstanding. Large collections of parasitized larch sawfly material have been made in Quebec for shipment to British Columbia and elsewhere, whilst through co-operation between the Dominion Entomological Branch and the Farnham House laboratory, Europe is being combed for parasites of the spruce sawfly. Considerable sums of money and a tremendous amount of work have already been expended by the Government on these projects. The Quebec Provincial Government and the Quebec Forest Industries Association, Ltd. have proffered financial assistance, but much remains to be done. The entire undertaking is somewhat in the nature of a wager, but the odds are favourable and no alternate course of action can possibly be chosen under the circumstances.

Thus far, parasites have been used mainly, if not exclusively, for the control of introduced pests. Under natural conditions, native parasites should regulate the numbers of injurious native insects. However, in the majority of regions where man has become the dominant species, natural conditions either do not exist any more or the operation of the natural balance falls short of man's purposes. Artificial interference, stimulation or regulation, becomes necessary either in speeding up the action of natural control agencies or in maintaining their ordinary efficiency. Although the introduction of foreign parasites for the control of native pests suggests itself as one of the most feasible methods of procedure, it should not be adopted without thorough investigation of both its possibilities and its dangers.

Finally, two very important considerations in connection with biological control should ever be taken into account. First of all, success cannot be expected to materialize over night. The process is always more or less slow. Under the most ideal circumstances, several years must of necessity elapse 
before the parasite population can he sufficiently built up to cope with the situation. Secondly, and as a corollary to the above, the importance of early discovery of outbreaks cannot be over-emphasized. It can be shown mathematically that the population of the host insect may continue to increase for a long time even when parasites are making rapid gains. The first factor in such a computation is, of course, the number of hosts at the time of the parasite introduction. By the same token we also know that the continued increase of hosts over a given period is not an indication of failure on the part of the parasites. In this respect biological control is in no way different from any other type of prophylaxis. In the past, the majority of important infestations were in an advanced stage before they were reported to any one. Sometimes the forest entomologists are blamed for this. It should be remembered that they are a mere handful, that all their time is devoted to research in an attempt to solve the problems submitted to them and that for the discovery of infestations they depend entirely on the co-operation of organizations, governmental or industrial, whose routine work involves a considerable amount of surveys and cruises. Recently, under the auspices of the Canadian Society of Forest Engineers, a committee on co-operation has been formed. So far as the entomological section of this committee is concerned, its principal usefulness to all concerned will consist in the development of a practical forest insect intelligence system through which, it is hoped, calamities such as Canada has experienced in the past, may be either greatly mitigated or completely forestalled.

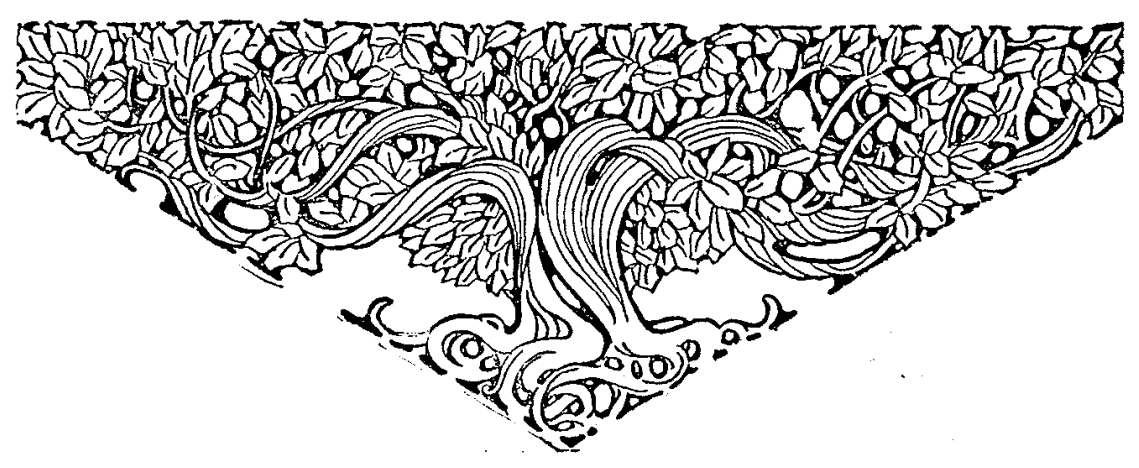

